\title{
REJECTION OF INDIGENOUS MUSIC? REFLECTIONS OF TEACHING AND LEARNING OF MUSIC AND DANCE IN TAMALE INTERNATIONAL SCHOOL
}

\section{Isaac Kwesi Mensah ${ }^{1}$ and Emmanuel Obed Acquah ${ }^{2}$}

${ }^{1}$ Department of Social Sciences, Bagabaga College of Education

${ }^{2}$ Department of Music Education, University of Education, Winneba

Cite this article:

Isaac K.M., Emmanuel O.A. (2021), Rejection of Indigenous Music?

Reflections of Teaching and Learning of Music and Dance in Tamale International School. African Journal of Social Sciences and Humanities Research 4(2), 7486. DOI: $10.52589 / A J S S H R-$ MUUUIJWV.

\section{Manuscript History}

Received: 23 April 2021

Accepted: 13 May 2021

Published: 19 May 2021

Copyright $\left({ }^{\circ} 2020\right.$ The Author(s). This is an Open Access article distributed under the terms of Creative Commons AttributionNonCommercial-NoDerivatives 4.0 International (CC BY-NC-ND 4.0 ), which permits anyone to share, use, reproduce and redistribute in any medium, provided the original author and source are credited.
ABSTRACT: Culturally responsive teaching and learning in schools creates an engaging and accessible learning environment that ensures continuity in the traditions of the people. One of the aspects of culture which engages students effectively in the learning process is music and dance. However, the instructional delivery of Music and Dance in Tamale International School scarcely includes the indigenous music content to a broader perspective. The paper was an investigation to find out how music and dance was taught in Tamale International School. It also highlights the attitudes of students towards the teaching and learning of Music and Dance. Using the cultural theory of Education as the theoretical framework, and a case study research design, participants were drawn from the pupils, the music teacher as well as the headteacher of the school. Interview and observation were the main instruments for the data collection. It was revealed that teaching of music and dance in the Tamale International School was a problem due to the fact that the school is one of the Western colonized schools with much historical orientation on Western music thereby relegating African music to the background. Attitudes of pupils towards the study of African music component of the music and dance syllabus being negative due to their religious background and the orientation received from their parents. Situated within the cultural education theory, the paper concludes that when students are given the opportunity to learn traditional music very often at school, it will help them to know theirs as Africans and embrace it in spite of their orientations from their religious background.

KEYWORDS: Tamale, African Music, Cultural Theory, International School, Story-Telling 


\section{INTRODUCTION}

Music has traditionally played an important role in African culture. It is essential in representing the strong African heritage and its importance can be seen in many aspects of the culture. Unlike many cultures today, ancient African cultures encompassed music into their everyday lives. Dance, story-telling and religious practices are all grounded on the music of the culture. African music is a utilitarian function used in vital aspects of life such as, a child's naming ceremony, initiation rites, agricultural activities, national ceremonies, war times, religious ceremonies and ceremonies for the dead (Mbiti, 2015). Introduction of Western Education in Ghana by the British and missionaries in particular made us understand that anything and everything African with regards to worship, dressing, food, language, music and musical instruments was devilish (Coe, 2005). Music and musical instruments that were taught in the schools in the colonial days were of the Western type with that of the African thrown off board. This historic factor is still prevalent in some international schools in Ghana. As Flolu and Amuah (2003, p. 4) stated, "As far as education is concerned, it will be difficult to distinguish between the activities of Christian missions and the Colonial administration". Both saw education as a means of accomplishing their own aims. In this regard, in spite of the various efforts to Africanize the Ghanaian music, music has still been taught in African schools within the framework of the European formal education system. That is why Boamajeh and OheneOkantah (2000) reiterated that it is very sad that African music has not been part of the school curriculum. The reason is that music studied in schools had little to do with the music performed and produced by the people and is completely devoid of the events and realities that African children encounter outside schools. In discussing the importance of providing learning experiences that help African children to acquire knowledge and understanding of the traditional music and dance of their community and of their neighbours, Nketia (1999) asserted that there has been the recognition and that if there is no preparation, the African may not be able to participate fully in the life of communities to which they belong. It is therefore evident that there is the need to consciously see the music of the African as very important to the African, for music they say, is life and for that matter, the life of the African will be incomplete should traditional music be taken out of his/her life. What is important is for education or schools to imbibe these cultural music into the students but the case is different from some international schools in Ghana, including Tamale International School.

Our preliminary study in the school revealed greatly that music teaching in the school does not follow the syllabus designed for Music and Dance for Ghanaian children. Again, it was realized in the preliminary study that whenever the school organized any function such as the OpenDay or Speech-and-Prize-Giving day, cultural groups from sister schools were rather invited to perform music and dance. This situation raised two important questions: 1 . How is music and dance taught in Tamale International School? 2. What are the attitudes of pupils towards the learning of music and dance in the school? These questions needed answers that could drive a trajectory of actions towards solving the problem. Addressing these two questions will reveal the nature of teaching of the subject in the school. Again, it is envisaged that administrators of the school would consider content and approaches for teaching music and dance in the school. 


\section{Theoretical Framework}

The work was guided by the Cultural Theory of Education used in the work of Gearing et al. (2011). According to this theory, music is universal, transmitted through generations, and usually performed in the presence of others, and of extreme antiquity. Thus, in this contemporary world, one cannot adequately comprehend the operations of any one education system in a community unless one comprehends as well the operations of the variety of education systems which coexist. While there is no inter-culturally valid definition of music, and the cover term music is found in only selected cultures, a number of presumptive universals indicate that musicality is a prominent and distinctive characteristic of humankind. All peoples engage in activities that we would call music, often in relation to play, and everywhere in relation to ritual (Bispham, 2018). All peoples of the world sing, an activity recognized on the basis of context or by cultural consensus as different from speech. Therefore, different cultures have some form of instrumental music as well, however rudimentary.

Music-making is necessarily a cultural performance because conventions about the structure of music, its instrumentation, context of performance and meaning are all learned. Musicmaking is a system of communication transmitted through ongoing trans-generational interaction (Davidson \& Emberly, 2012). Music-making is or implies a social performance, even when performed or listened to alone. The solitary performer often has an audience in mind. For example, when music students at North American universities practice alone in hermetic practice rooms, they are usually imagining an audience (Trehub et al., 2015). Trehub et al. commented on solitary music-making:

Solitary music-making for personal pleasure is likely to evoke memories of learning the piece (when, where and from whom) and previous experiences of playing and hearing it. Musical pieces, like performers, are saturated with contextual, social memory. Indeed, musical performances are socially and culturally situated, as a result, they come to be ethically saturated as well. Our deepest values may be implied by participation in a particular genre of music such as a hootenanny (populist), heavy metal concert (male machismo), rave (youth culture plus drugs) or European classical concert (upper-middle-class values and lifestyle). There are exceptions, of course, but the aforementioned stereotypes are more likely than not to apply to any given listener at a musical event. (p.96)

Drawing claims from this theory, it is palpable to say that cultural tendencies impact the way children participate in education. Teachers can engage their students effectively in the learning process if they know their academic abilities individually. If the cultural norms do not match the norms prevalent in the schools, it becomes worrying since the students are being trained to take up the challenges in their own community. Students and youngsters in cultural education learn to reflect upon their own culture, culture of others and culture in general (Ladson-Billings, 2014). It must be noted that cultural education is very important because it helps them to grow up and to function in a culture which has a clear identity ready for them. 


\section{REVIEW OF RELATED LITERATURE}

\section{Music Teacher Preparation}

The Ghanaian music teacher is supposed to, among other things, have some level of knowledge about traditional music and their performances that can help him/her to teach it with confidence. The teacher must be able to teach drumming, dancing, dance-drama and African literature (Mereku \& Ohene-Okantah, 2010). The methodology used by teachers to teach students about traditional music is also one of the challenges that are confronting the teaching of traditional music in Ghanaian schools. For instance, Nketia (1974) indicated that there are, of course, a number of problems concerning the organization and practice of music and dance in traditional society that the teacher will encounter as he/she compiles his/her materials or plans lessons and music learning activities. For example, in traditional societies, knowledge is acquired in slow degrees over a long period of time, while emphasis is laid on learning through oral tradition and practice, aided by texts and mnemonics rather than explicit theory or written notation. In the classroom context, some aspects of this learning process can be shortened, for the materials of music can be presented and acquired in a more systematic manner than it is done in traditional communities.

If African music is to be meaningful, it must be studied within the context of traditional African life. Like Maultsby (2000) contended that music is an integral part of the life of every African soon after birth. As a result, it should be given all the encouragement in formal education. According to Gooding and Ciampi (2011), since the teacher may not be competent to handle every aspect of the music, he or she must be prepared to bring experts from the community to help him or her and also ensure that his or her class is given the opportunity to observe musical events in community life. Traditional instruments and dance are sidelined. Learners grow up in a globally oriented socio-cultural environment and have lost interest in the playing of indigenous instruments (Herbst et al., 2003). Teachers must be clear at every stage of their work of which they want to do, where they want to go, and what they need to bring to the classroom in order to achieve their goals, otherwise they may find themselves floundering or devoting the time allotted to music for sing or singing and dancing and nothing else (Mahony \& Hextall, 2000). Nketia (1999) still commented on the philosophy of music education in Ghana:

the curricular and pedagogical decisions taken by the teacher involved in laying strong foundation can be effectively be applied if he or she is guided by a philosophy of music education that takes problems and issues, for such philosophies are generally intended to clarify the basic premise or set of ideas from which goals, objectives and principles for the systematic teaching of music in formal setting could be derived. (p.13)

According to him the formulation of such philosophies is generally guided by a vision of what music as a subject of instruction and learning experience can contribute to the intellectual, social and cultural development of the individual. He is of the view that this vision may in turn be inspired by:

(a) an intimate knowledge of the musical culture, including its range of materials and dance vocabulary, corpus of music and dance as well as concepts and values that guide music making, and 
(b) insights into the dynamic relationship between music and the society, including current intellectual or "ideological" trends in the environment in which music and dance are cultivated, such as multiculturalism, gender balance and the right of the individual to education.

\section{General Attitude towards Music Learning}

African children today in urban cities have grown up without knowing anything about traditional music. They were taught subjects like mathematics, English language, and Science from the basic level without knowing anything about traditional music. It will therefore be very difficult for students who had no knowledge about traditional music from the scratch (i.e. from nursery through lower and upper primary) to embrace traditional music in the Junior High School. Secondly, traditional music had not been presented to students by music teachers because of the teacher's lack of knowledge in it and this had caused students to lose interest in the music of their own localities. Nketia (1974) talked about the importance of providing learning experiences that enable African children to acquire knowledge and understanding of the traditional music and dance of their own environment and those of their neighbours:

for without this preparation, they may not be able to participate fully in the life of the communities to which they belong. When they attend a marriage ceremony, a funeral or a festival or go to the dance arena, they may look like strangers among their own people. (p.56)

It is generally known that in the days gone by, such knowledge was acquired directly in the community by going to events, observing and listening to performances of music, imitating dance movements, gestures and facial expressions and taking part, where possible, in the singing and dancing. Children were often encouraged to do this and were helped now and then by interested adults. Similarly, Nketia (1999) commented on how the continuity of musical tradition was ensured in the community:

Where special knowledge of a particular musical tradition or instrumental skill was required because of a role that a child might perform in the future as a member of a household whose duty it was to maintain that tradition, additional instruction was also given privately. It was through these processes that continuity of traditional musical cultures was assured. (p. 1)

Indeed, what the teacher provides will not only make up for any manifest deficiency in the upbringing of children but also strengthen their consciousness of identity (Onosko, 1992). They will learn to accommodate or appreciate other kinds of music, such as Western and Arabic music and their derivatives they encounter on radio and television, or India music they hear on films, without being overwhelmed or tempted to abandon their own or hybridize it beyond recognition (Stevens, 2008). It is not because students do not like traditional music as compared to Western music, but it is because there are no music teachers to teach them traditional music. Assuming traditional music and dance is performed in a school by expert traditional musicians and dancers from the communities, one will always see students around to enjoy the music and even try to imitate the various dances. Ampomah (2000) in his assertion for laying foundation of music education for the Ghanaian child gave the following opinion:

Through participation in community events, Ghanaian children learnt the music of their ethnic groups during the pre-colonial and colonial days. In 
contemporary context however, children, especially, those living in the urban areas have lost this informal type of education because of schooling. (p. 43)

Most students do not understand traditional music when it is being played, as well as the instrumental background of the music: the function of the various idiophones such as bells, castanets, rattles, etc., the supporting drums and the role of the master drummer. Most students do not also understand the various dance steps and signs or gestures of the dancer(s) and it is the duty of the music teachers to help the students in these areas. What should children do to have interest in traditional music, to perform music, listen and create in building an awareness of aspects of the music leading to the understanding of musical fundamentals? What should children also need to know about the background of songs, instruments and dances involved in performance, listening and creative experiences as well? (Koutsoupidou \& Hargreaves, 2009). As Gillborn (2003) suggested, children will need to know the local background of the instruments they learn about. Instruments need to be introduced using their indigenous names (example, dawuro instead of cowbell). As stated earlier, Boamajeh and Ohene-Okantah (2000) had held the view that it is not good that African music had not been part of general education up till now. They further indicated that African music taught in our schools nowadays has little to do with the music by the society and does not include events and realities that African children experience outside school, but the students rather look like foreigners when they hear African music. How should students be more creative and improvise beyond that of the expert traditional musicians and beyond what exists in a culture or community? (Kwami, 2005).

\section{Psychological Needs for Music Learners}

Music is viewed as an integral part of all children's lives. Children enjoy listening to music, singing, and humming. Music may effectively enhance the ability to cope with stress. Some scholars have suggested that indigenous music and music performance should be found in both music classes and regular education classrooms. They are of the view that integrating literature with musical content will help to bring books alive and that musical classrooms will encourage children to relate and participate in the activities (Giles et al., 1991). However, very few studies provided a comprehensive view of some disability categories such as autism (Sze, 2004), mental retardation (MR) or cognitive delays, attention deficit disorders (ADHD), learning disabilities (LD) and physical and other health impairments (POHI). Music is more than a leisure activity. It is more than verbal counseling. It is a sophisticated cognitive, linguistic, social and psychological treatment. Music provides a form of compensation for those with language impairments as well as a means of facilitating language development:

1. select a piece of music the student will enjoy.

2. assist the student to take part in the musical activities.

3. let the student learn the names of the instrument and identify them as such before playing.

4. expose students to learn the lyrics and the phonemes through singing.

5. create a conducive learning environment for all students by using a range of nonjudgmental and nonverbal activities.

6. ensure to accept vocal sound as a creative part of improvisation

7. let the student use vocal sounds that are spontaneously emitted and that are elicited from singing. 
Indeed, music creates physiological responses, which are associated with emotional reactions. Music explains the tension release sequence associated with emotional arousal (Robinson, (1994). The speed and intensity of the musical beat creates the different feelings in each type of song. The opportunity to play an instrument can be used as a reinforcer for on task behaviour. Music focuses on accuracy and attention. Learning how to play an instrument can improve attention, concentration, impulse control, social functioning, self-esteem, self-expression, motivation and memory.

\section{Materials for Teaching African Music}

One of the challenges confronting the teaching of traditional music is the lack of materials.

Gardner and Gardner (2008) also commented on the pursuit of both tangible and intangible forms of knowledge, including symbolic and conventional forms and said:

can contribute to the intellectual development of the child when they are systematically presented at appropriate levels as part of the learning experience. As all these areas of knowledge constitute the fundamentals of African music, the teacher must ensure that he/she is familiar with all of them and he/she does not lose track of the African perspective of his/her materials. (p.16)

In the same way, Boamajeh and Ohene-Okantah (2000) gave the assertion that the quality of equipment also affects the status of teaching traditional music. The school authorities should provide designated rooms for traditional music lessons and other musical activities or adequate space for ensemble and listening to traditional music performances and rehearsals. Cultural education embodies music education. Flolu and Amuah (2003) expressed that, similarly, music education can be regarded as part of cultural education in a broad sense. Suffice it to say that there are practical difficulties which need to be solved before the programme can be educationally meaningful. The first is the misconception of Ghanaian music. The syllabus lists elements of the rudiments and theory of Western classical music but suggests the use of Ghanaian songs in teaching these concepts. Where aspects from Ghanaian music are stated, the suggested activities are based on the same approach with which Western music theory is taught. The result is that Ghanaian music is presented to Ghanaian children in class as an imported material (Flolu \& Amuah, 2003).

Every cultural system has a set of ways of imparting knowledge to the younger generation. Learning African music requires, therefore, an understanding of the cultural system, the creative principles of the music and the methods by which that music is transferred from one person to another. Western art music is widely understood and appreciated because of a universal understanding and appreciation of Western cultures in general and in particular, the systems of imparting knowledge, (Nketia, 1974). Although music educators now advocate for the teaching of all music of the world, it will be educationally futile to subject all music to a particular system of learning. Continuous reliance on the Western approach is making even the teaching of African music in Ghanaian schools extremely difficult. Imagine the practice whereby indigenous Ghanaian music is presented to children in class as an imported material (Flolu, 2003). 


\section{METHODOLOGY}

The study was rooted in the case study research design. As posited by Creswell (2016), case studies are plans and procedures for the research that span the decisions from broad assumptions to detailed methods of data collection and analysis. The study was done in Tamale International School, Ghana. The school was established in the year 1972 by a German for the children of workers in his Mango processing factory with the view of the workers not giving excuses of sending their wards to school resulting in the workers reporting late to work. The curriculum was German oriented with music (Western music) being part. Due to good performance put up by the pupils of the school, elite parents who were not workers of the factory sent their wards to the school. The school remained a private one until 1994 when it was absorbed by Ghana Education Service and has since run the Ghanaian curriculum. The school has a student population of four hundred and thirty-two (432) at the Junior High School (JHS) level with eleven (11) teachers as tabulated below:

Table 1: Population of Students in Tamale International School as at 2018

\begin{tabular}{llccc}
\hline S/N & Class & Number of Girls & Number of Boys & Total \\
\hline 1 & JHS 1A & 36 & 34 & 70 \\
2 & JHS 1B & 32 & 42 & 74 \\
3 & JHS 2A & 35 & 37 & 72 \\
4 & JHS 2B & 38 & 34 & 72 \\
5 & JHS 3A & 35 & 36 & 71 \\
6 & JHS 3B & 35 & 38 & 73 \\
\hline & Total & $\mathbf{2 1 1}$ & $\mathbf{2 2 1}$ & $\mathbf{4 3 2}$
\end{tabular}

Table 2: Population of Teachers in Tamale International School as at 2018

\begin{tabular}{llc}
\hline S/N & Class & Number \\
\hline 1 & Mathematics & 2 \\
2 & English & 1 \\
3 & Science & 1 \\
4 & Basic Design \& Technology & 2 \\
5 & Ghanaian Language \& Culture & 3 \\
& Information and Communication Technology & 1 \\
\hline & $\quad$ Total & $\mathbf{1 0}$
\end{tabular}

There is one headteacher who makes the number of teachers eleven (11). One of the teachers for Ghanaian Language and Culture is responsible for music and dance teaching. 20 students from JHS one and two classes were randomly sampled for the study. The 20 students were made up of 5 girls and 5 boys from each class. In addition, the music teacher and the headteacher were purposely sampled and used for the study. The music teacher was selected because of the subject he teaches while the headteacher was also selected as a result of his position as a headteacher who could also give information about the subject teaching situation in the school. In collecting data for the study, focus group discussions were done with the students. Students were grouped into 4 groups of 5 to detail issues about their knowledge in their own music and how they participate in music lessons. The essence was to ascertain their 
interest level and attitudes towards music and dance learning. The music teacher and the headteacher were also interviewed one - on - one. The purpose was to solicit information on the state of the Ghanaian music learning in the school and in the classroom. All these outcomes were recorded with a tape recorder and where necessary, written in a notebook. Proceedings in class with regards to the methodology and approaches the teacher uses to teach music were observed. Observation also included the content of the music instruction delivered at any point in time. A couple of music lessons in the two classrooms were observed. Teacher's delivery techniques as well as students' attitudes toward the lessons were noted.

\section{DISCUSSION OF FINDINGS}

It was found out that the knowledge of the teacher in the music subject matter was minimal and therefore found it difficult to handle the syllabus. The teacher for instance said this:

I cannot teach African music because that is not what we are supposed to teach here. Again, there are no teaching and learning resources that $l$ can rely on to aid my handling of the subject since African music involves lots of drums. I cannot dance, so I have that deficiency to handle music performance. (Teacher participant)

Again, it became evident that the school had created a culture where anything African was seen as fetish. Western culture including music is what permeates the life of the school. The reason was attributed to historical effect. Commenting on this the teacher had this to say:

I joined the school to find that the type of music taught in the school was strictly the Western type of music and this was handled by the proprietor himself. Ever since the school was absorbed by the government where the music curriculum changed, it has become a challenge to me in particular. In fact, the Western music type has eaten into the fiber of the school such that the pupils feel reluctant studying the African type of music. (Teacher participant)

The headmaster corroborated this but gave an exception that local dances are rather learnt for special school programmes. Usually, they fall on resource persons to sometimes come and train the pupils for such programmes. Pupils usually have bad attitudes towards these resource persons but they forcibly do it and achieve good results consequently. The headmaster said:

I was posted to the school barely two years ago and so l have no much information pertaining to which type of music the school studied before. In terms of the current curriculum, my knowledge about it is very limited and l have not taken pains to go through the syllabus to acquaint myself with it. Anytime the school is going to have a programme, resource persons are brought from the community to teach selected students some of the local dances for performance purposes. (The headteacher participant) 
Focus group discussions with the pupils revealed why the study of the African music is a problem in the school. They attributed it to the Christian background of their parents and their own little knowledge about African music as much as studying music and dance in their school is concerned. One of the students said:

\section{I am from a Christian home. My father is a pastor who has taught us that we should not involve ourselves in traditional dance because they are for the gods. Because of this, I dislike music and dance. (Student participant)}

Another pupil commented on how they are naïve about the importance of their cultural music and how it is not spoken about at home or school. She retorted:

Traditional music and dance in my home is least spoken about not to talk of playing and listening to it and so it is alien to me.

(Student participant)

When asked whether they have been watching any traditional music performance in their hometown, one of the pupils said this:

My parents do not go with me to my hometown ever since I was born so l do not know of my culture and any other culture that involves singing, drumming and dancing. What I know is that, some people from the town come here at times to teach some few students to dance when we are having school programmes.

\section{(Student Participant)}

It came to light after the interview sessions with the pupils that their religious backgrounds contributed largely to their lukewarm attitude towards the teaching and learning of music and dance in the Tamale International School. Observation made at music and dance classes was evident that many of the lessons usually centred on Western music than the component of the African music. In one of the lessons we observed during the second visit, we asked the teacher to include a component of the African music in the lesson delivery. During such classes some of the students left the class with the intention of visiting the washroom but did not return till the class ended.

Generally, bringing music from the traditional sector into the formal setting could have challenges. Efforts are being made but the results are not being realized. The need was seen by the colonial masters and the traditional educationists that the music curriculum should be Africanized. Attempts had been made for traditional music to be taught in the various Ghanaian schools but this has not been achieved owing to several challenges. If Africanization is desirable and yet there have not been solutions for music and dance to be part of the curriculum, this means there are challenges which need to be investigated and appropriate solutions suggested (Appiah, 2015). Furthermore, the classroom teacher must now provide children with growing-up experience, for teaching traditional music in the classroom can be one of the ways of ensuring continuity of cultural transmission. What the teacher provides will not only make up for any manifest deficiency in the upbringing of children but also strengthen their 
consciousness of identity (Nketia, 1999). The researchers were able to know that this problem of the challenges of teaching traditional music may exist in some Ghanaian schools.

It can be inferred that the music teacher lacks the needed knowledge in the Ghanaian traditional music to be able to deliver. If the teacher does not know his stuff, in what way can he impart? (Russell-Bowie, 2009). This was known to the researchers as a result of the interview conducted with both the students and the teachers in the schools. As stated earlier, children everywhere in the world deserve to have music as another element of their communication of ideas, emotions, and who they are (Woodford, 2005). Consequently, it has been said by many musicologists in the West and Zoltan Kodaly--that music is a right of the child, a right to use music as an element just as speech (Swanwick, 2002). Just as being a literate person is a right for people, so too music expression and using music and having a feeling for music is a right (Hays \& Minichiello, 2005). Children really deserve the right to use music of their own culture (Nketia, 1999).

The introduction of education in Africa by the missionaries and the colonial masters and the rapid economic and social changes in Africa today had caused many children living in big cities and towns to lack the knowledge of traditional music of their own people. This is as a result of teachers' having the notion that everything about African culture of which traditional music is part of this culture, is devilish. It is the duty of the classroom teacher to know traditional music so that he/she can in turn help these children who do not know anything about traditional music. Teaching traditional music in the classroom to the children can be one of the ways that our culture continues to be passed on from one generation to the other (Green, 2002).

It is worth stating that the students' negative attitude to traditional music is due to the inability of the music teachers who are not able to teach them several traditional music and dance. The few dances which the teachers know and always teach become boring to the students because of the monotony of the dances. These anomalies had been caused by the kind of culture created in the school. During sporting activities by the private schools, "Jama" music and dance is performed and a lot of students participate in the singing and dancing. Jama music is a type of music which is performed with traditional musical instruments like the various African drums, bells (cowbell or slit bell), claves and rattles. This cultivated experience in Jama music performance could be transferred into the classroom and formalized. As Nketia (1999) explained, for children to have interest in traditional music, they need to perform music, listen and create in order to build an awareness of aspects of the music leading to understanding of musical fundamentals. They need to know about the background of songs, instruments and dances involved in performance, and have listening and creative experiences, as well.

\section{CONCLUSION}

When students are given the opportunity to learn traditional music very often at school, it will help them to know theirs as Africans and embrace it in spite of their orientations from home and religious background. They will be pleased to learn the various traditional musical instruments such as Atenteben, Seperewa, Prenpensuwa, Xylophone and the rest. They will also be happy to learn the various traditional drums but because the opportunity is not given them, they seem to doubt the existence of African music in the space of time. 
Furthermore, if teachers go through orientation to teach the African traditional music, their minds will be disabused from the prejudices and misconceptions which they may have acquired because of their Western training, through the church and the aftermath of colonial education. Teachers will now be resourced to handle music topics that connect the Ghanaian culture. This can be a booster to the students to change their attitudes positively towards indigenous music learning for posterity.

\section{REFERENCES}

Ampomah, K. (2000). The Changing Role of Traditional Ghanaian Music: Implications for Primary Music Education in Ghana. African Music Educator, 10, 17-31.

Appiah, F. K. (2015). Challenges of teaching traditional music in Ghanaian schools study of three selected private schools in Kasoa (Doctoral dissertation, University of Education, Winneba).

Bispham, J. C. (2018). The Human Faculty for Music: What's special about it? (Doctoral dissertation, University of Cambridge).

Boamajeh, C.Y., \& Ohene-Okantah, M. (2000). An Introduction to Music Education for MusicTeachers in Schools and Colleges. Payless Publication Ltd.

Coe, C. (2005). Dilemmas of culture in African schools: Youth, nationalism, and the transformation of knowledge. University of Chicago Press

Creswell, J. W., \& Poth, C. N. (2016). Qualitative inquiry and research design: Choosing among five approaches. Sage publications.

Davidson, J., \& Emberly, A. (2012). Embodied musical communication across cultures: singing and dancing for quality of life and wellbeing benefit. Music, health and wellbeing, 136-149.

Flolu, J. (2005). An ethnic approach to music making as a strategy for teaching African music: The need for systematic research. Emerging solutions for musical arts education in Africa, 108-113.

Flolu, J., \& Amuah, I. (2003). An introduction to music education in Ghana for universities \& Colleges. Black Mask Ltd.

Gardner, H., \& Gardner, E. (2008). Art, mind, and brain: A cognitive approach to creativity. Basic Books.

Gearing, F., \& Sangree, L. (Eds.). (2011). Toward a cultural theory of education and schooling. Walter de Gruyter.

Giles, M. M., Cogan, D., \& Cox, C. (1991). A music and art program to promote emotional health in elementary school children. Journal of Music Therapy, 28(3), 135-148.

Gillborn, D. (2003). Race, ethnicity and education: Teaching and learning in multi-ethnic schools. Routledge.

Gooding, J. J., \& Ciampi, S. (2011). The molecular level modification of surfaces: from selfassembled monolayers to complex molecular assemblies. Chemical Society Reviews, 40(5), 2704-2718.

Green, L. (2002). How popular musicians learn: A way ahead for music education. Ashgate Publishing, Ltd.

Hays, T., \& Minichiello, V. (2005). The meaning of music in the lives of older people: A qualitative study. Psychology of music, 33(4), 437-451. 
Herbst, A., Josephs, D., Kahindi, A., \& Miya, F. (2005). Musical arts education in Africa: A philosophical discourse. Emerging solutions for musical arts education in Africa, 1123.

Koutsoupidou, T., \& Hargreaves, D. J. (2009). An experimental study of the effects of improvisation on the development of children's creative thinking in music. Psychology of Music, 37(3), 251-278.

Kwami, R. (2005). Indigenous African music in a relocated context: A case study. Emerging solutions for musical arts education in Africa, 153-162.

Ladson-Billings, G. (2014). Culturally relevant pedagogy 2.0: aka the remix. Harvard Educational Review, 84(1), 74-84.

Mahony, P., \& Hextall, I. (2000). Reconstructing teaching: Standards, performance, and accountability. Psychology Press.

Maultsby, P. K. (2000). Africanisms in African American Music. A turbulent voyage: Readings in African American studies, 156-176.

Mbiti, J. S. (2015). Introduction to African religion. Waveland Press.

Mereku, C.W.K., \& Ohene-Okantah, M. (2010). Music and dance for the basic school teacher. Institute for education development and extension (UEW).

Nketia, J.H.K. (1974). Music of Africa. W.W. Norton \& Company.

Nketia, J.H.K. (Ed.) (1999). A guide for the preparation of primary school African music teaching manuals. Afram Publications (Ghana) Limited.

Onosko, J. J. (1992). Exploring the thinking of thoughtful teachers. Educational Leadership, 49(7), 40-43.

Robinson, J. (1994). The expression and arousal of emotion in music. The Journal of Aesthetics and Art Criticism, 52(1), 13-22.

Russell-Bowie, D. (2009). What me? Teach music to my primary class? Challenges to teaching music in primary schools in five countries. Music Education Research, 11(1), 23-36.

Stevens, C. S. (2008). Japanese popular music: Culture, authenticity, and power (Vol. 9). Routledge.

Swanwick, K. (2002). Musical knowledge: Intuition, analysis and music education. Routledge.

Sze, S., \& Yu, S. (2004). Effects of music therapy on children with disabilities. In The Proceeding of the 8th International Conference on Music Perception \& Cognition. Adelaide, Australia: Causal Productions.

Trehub, S. E., Becker, J., \& Morley, I. (2015). Cross-cultural perspectives on music and musicality. Philosophical Transactions of the Royal Society B: Biological Sciences, 370(1664), 20140096.

Woodford, P. (2005). Democracy and music education: Liberalism, ethics, and the politics of practice. Indiana University Press. 